\title{
EFFECTIVE INNOVATION IMPLEMENTATION OF MECHATRONIC PRODUCT-SERVICE SYSTEMS CONSIDERING SOCIO-TECHNICAL ASPECTS
}

Koltun, Gennadiy Dmitrovic (1); Romero Viturro, Carlos Alberto (2); Buchholz, Johan (1); Wissel, Juliane (1); Zaggl, Michael (1); Ocker, Felix (1); Vogel-Heuser, Birgit (1)

1: Technische Universität München, Munich, Germany; 2: Universidade de Vigo, Vigo, Spain

\begin{abstract}
It is estimated that about half of all innovations, such as innovations in mechatronic product-service systems (PSS), fail to deliver the expected benefits to the adopting organization. Different studies point out that one of the main reasons for this is an ineffective implementation process.

In this paper, we argue that, apart from several organizational challenges, insufficient integration of technical and social aspects is one of the reasons for ineffective innovation implementation in the environment of mechatronic PSS.

In order to remedy this weakness, this paper builds on the work of interdisciplinary research collaboration. Experts from technical, socio-technical, and management fields integrate their work within a conceptual innovation implementation management system (IIMS). This IIMS is capable of capturing various methods and models that foster the socio-technical integration in mechatronic PSS. The approach is assessed in a lab-scale demonstration case that is representative of industrial environments.

The presented approach supports an effective innovation implementation process, while the IIMS facilitates individual alignments for future practitioners.
\end{abstract}

Keywords: Product-Service Systems (PSS), Mechatronics, Design engineering, Innovation Implementation, Socio-technial Innovation Design

Contact:

Koltun, Gennadiy Dmitrovic

Technische Universität München

Institute of Automation and Information Systems

Germany

gennadiy.koltun@tum.de

Cite this article: Koltun, G.D., Romero Viturro, C.A., Buchholz, J., Wissel, J., Zaggl, M., Ocker, F., Vogel-Heuser, B.

(2019) 'Effective Innovation Implementation of Mechatronic Product-Service Systems Considering Socio-Technical

Aspects', in Proceedings of the 22nd International Conference on Engineering Design (ICED19), Delft, The Netherlands,

5-8 August 2019. DOI:10.1017/dsi.2019.312 


\section{INTRODUCTION}

\subsection{Motivation and field of investigation}

Due to increasing globalization and market competitiveness (Neely, 2007), companies have to provide a custom-tailored product and service portfolio (Aurich et al., 2006) and perceive growing pressure to be innovative. This leads to high variability of product and service types, including a combination of both-the so-called Product-Service System (PSS).

One example are mechatronic PSS such as automated Production Systems (aPS), which consist of numerous mechanical, electrical/electronic, and software components (Kernschmidt and Vogel-Heuser, 2013). According to Reif et al. (2017), innovations in mechatronic PSS often imply changes and require the harmonization of these technical components and the involved stakeholders. In this paper, we address socio-technical systems in the context of mechatronic PSS, in particular aPS, for the following two reasons: (a) Within mechatronic PSS, different discipline-specific and interdisciplinary dependencies between components exist. Changes due to innovation require interoperability and compatibility of components. These components are developed by various stakeholders, i.e. engineering disciplines, which is why collaboration is essential. (b) Apart from the technical aspect, a given system works within a human collaborative context, which brings further aspects into focus: The rules, customs, and practices that are used in the context of a mechatronic PSS. Since implementation takes place inside an organization, specific social theories can contribute to the enrichment of a socio-technical perspective on PSS. This socio-technical perspective, which considers not only technical aspects but also organizational and other aspects from the social environment, in which a given technology is embedded, is often neglected. This is one reason for ineffective implementation of innovations in both technical system and organizations. As a consequence, we aim at emphasizing the importance of the integration of both technical and organizational aspects during the entire life-cycle of mechatronic PSS.

\subsection{Problem statement and research questions}

Estimates exist that about half of all innovations fail to provide the expected benefits to the adopting organization (Aiman-Smith and Green, 2002; Repenning, 2002). This is not caused by the ineffectiveness of the innovation itself, but by an ineffective implementation process (Klein and Knight, 2005; Amaya et al., 2018). Many studies on innovation consider innovation adoption as the end of the innovation process, overlooking that innovations do not create a competitive advantage unless they are effectively implemented (McGrath et al., 1996). Even the CEN/TS 16555-1 technical specification published by the European Committee for Standardization (CEN, 2013) that provides guidance on the establishment and maintenance of innovation management systems does not address innovation implementation.

Referring to mechatronic PSS, ineffective innovation implementation comes with an increased workload and requires additional effort within the organization to achieve certain formulated goals. The importance of context factors of when a technical system is applied within an organization has been highlighted (e.g. Avgerou (2001); Gunasekaran et al. (2001); Zaggl et al. (2019)) and is therefore also of relevance when it comes to the implementation of mechatronic systems in organizations. Having a look at the technical perspective, ineffective innovation implementation is characterized by repetitive changes accompanied by compatibility and consistency challenges (Reif et al., 2017; Koltun et al., 2018). A lack of consideration of technical and socio-technical implications is associated with mostly unwanted side-effects.

To address the issue of ineffective innovation implementation in the context of collaborations in mechatronic PSS, we pose the following research questions: How can effective innovation implementation be fostered in mechatronic PSS? How can technical and organizational aspects be integrated during the life-cycle of mechatronic PSS?

\subsection{Contribution and structure of the paper}

Although the Problem Statement can be applied to any field, we provide detailed insights in the context of mechatronic PSS (i.e. Automated Production Systems) in this paper.

Furthermore, our research is based in the context of an interdisciplinary research collaboration that investigates the cyclical nature of innovations (CRC 768: "Managing Cycles in Innovation ProcessesIntegrated Development of Product-Service-Systems Based on Technical Products"). The research 
collaboration provides valuable insights for interdisciplinary collaboration in socio-technical systems. This paper provides the following main contributions:

- Socio-technical understanding of ineffective innovation implementation in mechatronic PSS

- Innovation implementation approach put into action with a developed Innovation Implementation Management System (IIMS)

- Assessment of the approach in a representative demonstration case for industrial environments The remainder of the paper is structured as follows: section 2 presents the relevant background in terms of challenges. It subsequently introduces a demonstration case as representation for innovation implementation in mechatronic PSS. Section 3 provides the conceptual approach for innovation implementation emphasizing the capability to integrate technical and socio-technical aspects. Section 4 comprises the feasibility study of this approach in the demonstration case, followed by the validity assessment regarding industrial applicability. Finally, section 5 concludes with a summary and an outlook for future research.

\section{Challenges AND RePRESENTATIVe CASE StUdY}

In this section, we first present the challenge derived from literature related to innovation implementation. Subsequently, we refine the challenge with regard to innovation processes in the domain of mechatronic PSS. Finally, we present a representative case study that serves as a basis for the assessment of the proposed concept for effective innovation implementation in mechatronic PSS.

\subsection{Challenges and related work}

\section{Challenge 1: effective innovation implementation}

To understand effective innovation implementation, it is essential to understand what an innovation is. Furthermore, it is important to distinguish between innovation adoption and innovation implementation (Klein and Knight, 2005). Internationally recognized organizations such as OECD and EUROSTAT define innovation in the Oslo Manual (OECD, 2005) as

the implementation of a new or significantly improved product (good or service) or process, a new marketing method, or a new organizational method in business practices, workplace organization or external relations.

Adopting an innovation means deciding to use it. Innovation implementation, on the other hand, refers to the phase between the adoption and the routine usage of an innovation

during which [individuals] become increasingly skillful, consistent, and committed (Klein and Sorra, 1996).

Most of the relevant literature does not consider sustainability when talking about innovation implementation, although it is a critical factor, especially its economic aspect (Teece, 1986; Moore et al., 2017). Therefore, this paper defines effective innovation implementation as the process of integrating an innovation in an organization in a way that ensures the sustainable achievement of the required functions, creating a competitive advantage and generating an economic benefit for the organization.

Innovation research has identified several reasons for why an effective innovation implementation is challenging for organizations, e.g. the need to develop additional skills to use the innovation (AimanSmith and Green, 2002), the required change of roles and routines in the company (Adolfsson et al., 2004; Amaya et al., 2018), and the high financial and temporal expenditures associated with the innovation (Repenning, 2002). Though these challenges of innovation implementation are well known, nowadays companies face additional problems, e.g. they are often more open and interconnected with their ecosystem (Zaggl et al., 2019).

The aforementioned challenges are addressed in (Klein and Sorra, 1996) by introducing a model which expresses that the key for effective innovation implementation is to consider how the influence of the implementation climate and innovation-values fit in an organization. Moreover, research identified several further factors that are essential to enable an effective innovation implementation from an organizational perspective, e.g. top management support and a long-term orientation. Additionally, organizations have to provide sufficient financial resources for innovations (Klein et al., 2014) and give their employees the opportunity for further education (Edmondson et al., 2001).

Although the above-mentioned model has been empirically validated in numerous studies (e.g. Dong et al. (2008)), it has a high level of abstraction, meaning it is not specific enough to ensure effective 
innovation implementation in a specific organization. Consequently, we aim at developing an approach to enable effective innovation implementation with regard to mechatronic PSS in this paper, based on a management system. One of the main benefits of management systems is that they provide a clear and efficient operation framework that outlines procedures to achieve certain requirements (ISO, 2001).

\section{Challenge 2: innovation process management of mechatronic PSS}

In the authors' collaborative research center ${ }^{1}$, we understand an innovation to be the result of qualitatively new products or processes that a PSS has noticeably changed and successfully introduced into the market. In order to describe an innovation process from design to the successful use, a model consisting of seven discrete phases has been developed (for a detailed description, we refer to Langer and Lindemann (2009)).

Since 2008, 47 methods and models that support the management of innovation processes have been developed within the authors' research center. The research collaboration investigates the cyclic nature of innovations and includes a wide range of innovation-relevant disciplines (e.g., product development, information systems, technology and innovation management, automatic control engineering, mechatronic automation and information systems, economic and organizational psychology, and sociology). To analyze how this innovation process is supported by these methods and models, we applied two steps. First, we assigned the approaches to the innovation process phases in workshops. Secondly, we applied the Design Structure Matrix (DSM) (for a detailed description, we refer to (Browning, 2001)). The resulting degree of dependencies is depicted in figure 1. It can be seen that production (technical phase) and introduction (organizational/societal phase) that cover innovation implementation are still insufficiently integrated. This also reflects the results from other recent research studies. We therefore endorse socio-technical innovation processes of mechatronic PSS in this paper through the concept of Institutional Reflexivity, i.e. the process of continuously monitoring and adjusting (Moldaschl, 2007) the emerging organizational forms of cycle management.

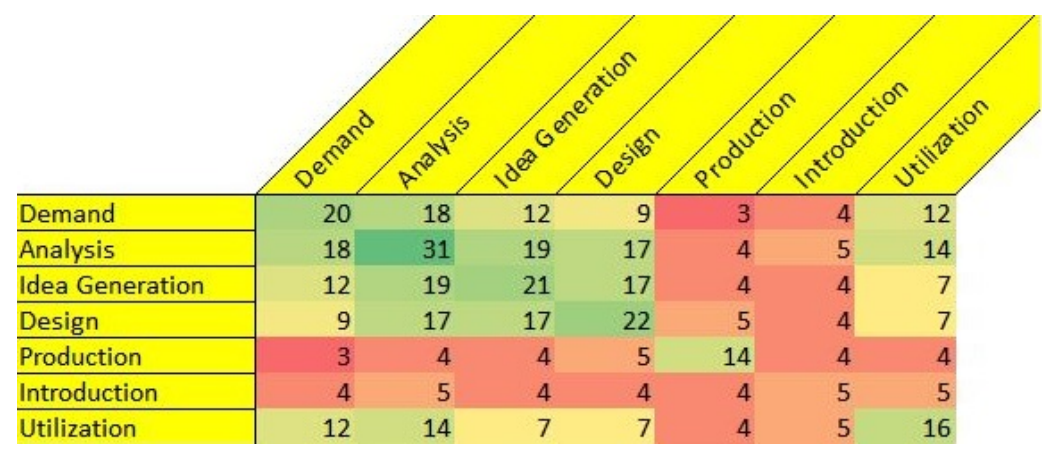

Figure 1. DSM of 47 models from the authors' research center that are classified into innovation process steps. For these steps, the DSM is indicating (production and integration phases) low integration of technical and organizational aspects (red areas).

\subsection{Representative case study and socio-technical success factors}

In the following, we introduce a lab-scale demonstrator to represent a mechatronic system: namely, the extended Pick and Place Unit (xPPU) (Vogel-Heuser et al., 2014). The xPPU handles and manipulates different work pieces. Such an aPS consists of different interacting components, i. e. mechanics, electrics/electronics and software. These components are characterized by different lifetimes. Software, for example, is updated more frequently than electrics and mechanics. Since innovations change such a multidisciplinary interdependent system (Koltun et al., 2018), numerous technical challenges must be met (e.g. variant \& version management and inconsistency management (Feldmann et al., 2004)). However, modern mechatronic systems become mechatronic PSS and therewith further multitude stakeholders are involved during the life-cycle of those mechatronic PSS. For instance, technicians maintain such a system, while the sales staff sells products and services of the system (cf. Figure 2). Therefore, organizational collaboration is essential for the maintenance of such a complex system that includes

${ }^{1}$ https://www.sfb768.tum.de/en/home/, retrieved on 16/12/2018. 
technical components but also organizational practices and rules, e.g. the extent to which the distribution department can make decisions on production capacity or how errors are communicated within a specific department. Each organization has its own set of formal and informal rules and practices (Friedberg, 1997) that enable the organization to function in a specific way. Furthermore, these local contexts are crucial when it comes to change and innovation in organizations. These formal and informal rules can differ between organizations even though the physical infrastructure, such as a mechatronic system, is similar or the very same. As a consequence, an effective innovation implementation approach that has been shown to be effective in organization $\mathrm{X}$ may be ineffective in organization $\mathrm{Y}$ if sociotechnical aspects have not been considered thoroughly. As these organizational aspects enhance a purely technical perspective and encompass the social context in which the technology is embedded, we refer to these dimensions in the following as socio-technical aspects. Even though we are aware that more socio-technical dimensions such as team-aspects can be included into an innovation implementation management framework, the aforementioned organizational approach serves as a starting point for further investigation. Consequently, this paper provides an innovation implementation management framework that can be adapted within an organization according to its specific characteristics and needs to link technical and organizational resources, to establish policies, and to define appropriate objectives.
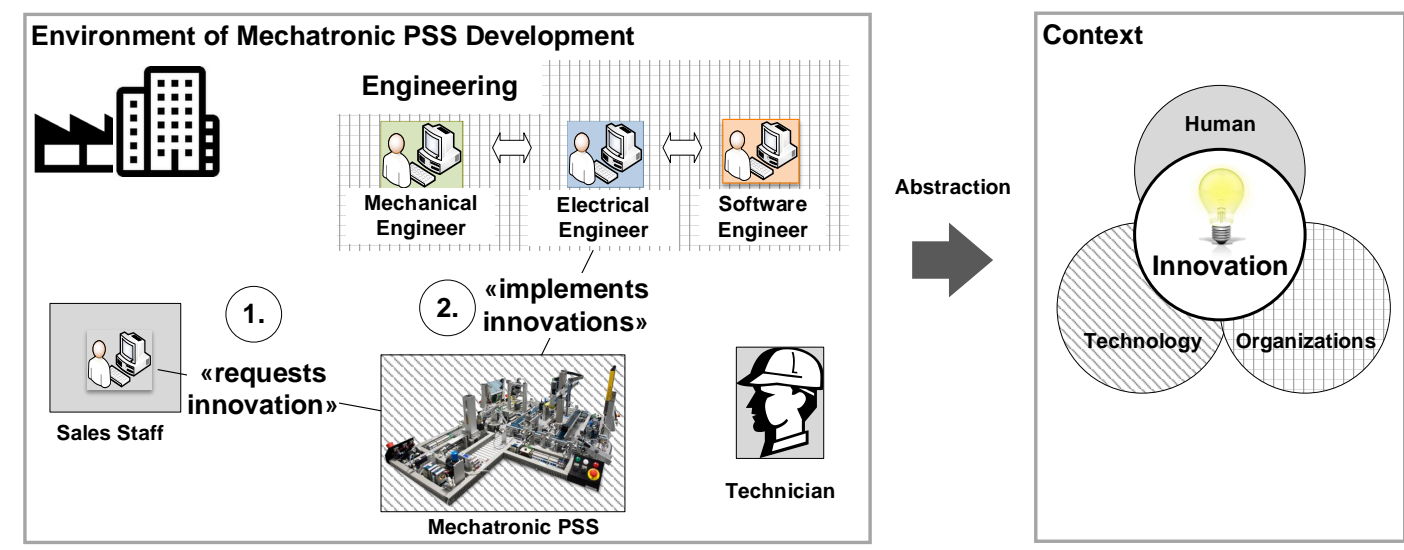

Figure 2. Mechatronic PSS supplemented by human stakeholders and organizations to demonstrate the necessity of socio-technical aspects during innovation implementation.

\section{CONCEPT}

This section introduces an approach for managing innovation implementation processes in the context of mechatronic PSS (cf. challenges in section 2). This approach aims at transforming innovation implementation requirements (i.e., what is intended to be achieved with the implementation) into a competitive advantage for a mechatronic PSS organization.

In order to meet the general conditions of innovation implementation, section 3.1 introduces the innovation implementation context. Section 3.2 presents the actual structure of the innovation implementation process. Both the innovation implementation context and the innovation implementation process are managed by the Innovation Implementation Management System (IIMS) in subsection 3.3, which is the cornerstone of this approach. Finally, section 3.4 introduces key performance indicators, which are essential to transform measured data about the degree of the innovation implementation process effectiveness into feedback information for the IIMS. Figure 3 depicts the conceptual overview.

\subsection{Innovation implementation context}

The need to define an innovation implementation context arises due to the fact that certain activities are needed for the innovation implementation process to be carried out, but cannot be considered part of it since they do not have to be performed every time (such as the designation of responsibilities and authorities or innovation implementation policies and practices). Socio-technical aspects, i.e. organizational practices, formal and informal rules can facilitate or hinder the successful implementation and are therefore crucial aspects during the analysis and definition of the innovation implementation context. 
The innovation implementation context shall be closed-loop, since it must be updated every time the innovation implementation process is not considered effective enough. As a consequence, this allows to optimize the innovation implementation context together with the innovation implementation process through continuous improvement. Moreover, in order to detect further opportunities of improvement, in-depth process reviews, such as those provided by audits, are strongly recommended.

In short, what the innovation implementation context provides is a framework of operations that are already being performed every time the innovation implementation process starts. This reduces the number of operations to be performed within the innovation implementation process to a minimum, making it faster and easier (and therefore more likely to be effective).

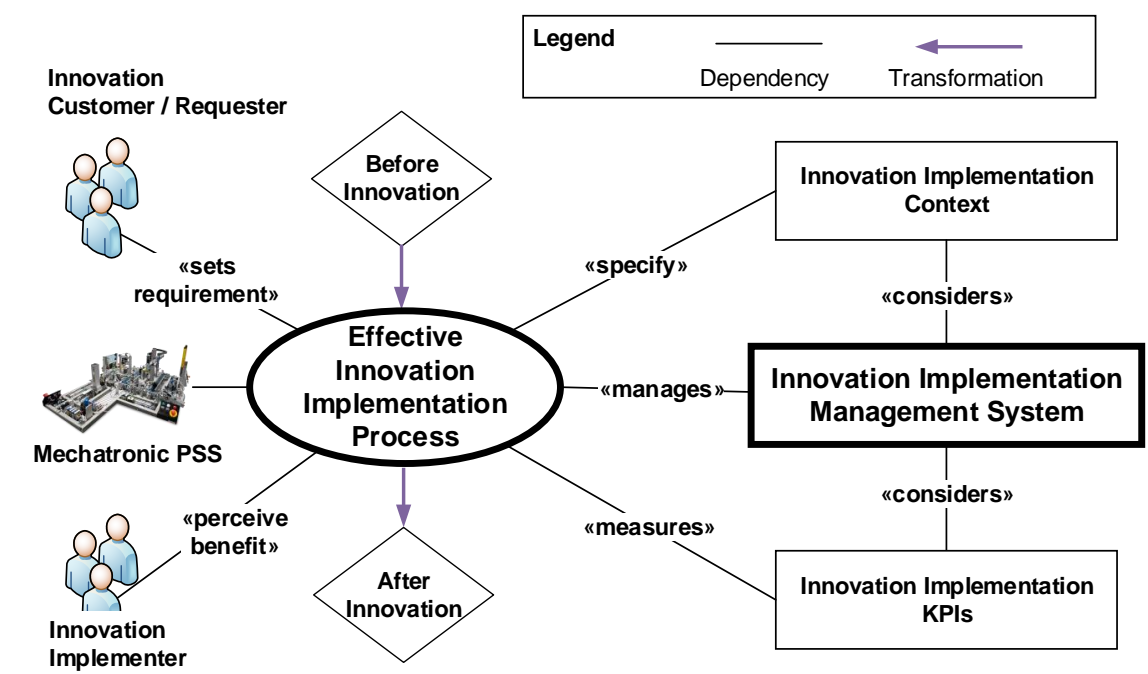

Figure 3. Overview on the conceptual approach for effective innovation implementation.

\subsection{Effective innovation implementation process}

As mentioned in Challenge 2.2, each company is a unique entity. This implies that there is no specific innovation implementation process that will fit every organization or, in other words, that a different specific innovation implementation process has to be developed for every organization.

In this paper, we aim to provide guidance in terms of a general innovation implementation process. We are therefore partially basing it on the "determinants and consequences of implementation effectiveness" model developed by Klein and Sorra (1996).

To model an innovation implementation process, we built a flow chart model with decision points. Each block represents an operation and must be broken down into concrete and unambiguously defined operations, i.e. who has to do what until when and how can this be checked. The structure of the flow chart is inspired by the "determinants and consequences of implementation effectiveness" model developed by Klein and Sorra (1996), i.e. the operations of the flowchart model can be classified as climate / context, innovation value fit, commitment, strategic, domain-specific, or measurement operations. Furthermore, the developed implementation process model can be extended by both a discipline-specific technical model and human behavioral models. Within the feasibility study (section 4.1), we outline the integration of technical and organizational aspects.

\subsection{Innovation implementation management system (IIMS)}

To apply the innovation implementation process and context models (see the prior sections), a realization framework - the so-called Innovation Implementation Management System (IIMS) - is required. We decided to develop a management system inspired by the ISO 9001 standard (ISO, 2015) in this paper that can impact the organization's ability to satisfy this requirement. Note, this IIMS will be only shared between stakeholders who are directly related to a particular innovation.

The IIMS is organized by procedures. A procedure is the description of the interrelated processes and operations required to implement a management system. Each procedure is divided into cover, generalities, sections and, if necessary, appendices and references. 
To increase the usability of such an IIMS, each cover has a blue background so that the start of the procedure can easily be identified. Furthermore, each procedure contains a title and administrative information such as authors, editors, revisions, and important dates at the beginning. Note, this information is partially taken from the innovation implementation process and context model.

The generalities include the purpose of the procedure, the scope of the procedure's application, the responsibilities in regard to the procedure's implementation, the definition of relevant terminology, and the boundaries for revisions within a certain procedure.

Each section (of a particular procedure) contains parts of the innovation implementation model in form of a flow chart. Furthermore, relevant operations are explained in order to guide the innovation implementation process. Relevant appendices and references are directly attached to a particular procedure. Only information that is relevant for the implementation of a procedure is collected.

\subsection{Key performance indicators}

To measure the fulfillment of requirements and therewith the progress of an innovation implementation process, we demand the definition of key performance indicators (KPIs). Knowing the degree of requirements fulfilled at any time is essential for two main reasons. On the one hand, it facilitates control if the sustained effects of the implemented innovation are maintained. On the other hand, it supports taking the necessary corrective actions if they are not maintained.

Although KPIs can be defined as absolute values (e.g. system downtime) on some occasions, they are usually defined as ratios, i.e. dividing the new value of the implementation objective (after the innovation implementation) by its old value (before the innovation implementation) and then subtracting 1 from the result of such division. For details about KPIs, we recommend further literature, e.g. (Eckerson, 2006). In this paper we highlight that the areas of acceptance and boundaries of the KPI measurements must be defined differently from organization to organization.

\section{RESULTS AND DISCUSSION}

This section is devoted to the discussion of the proposed approach. Therefore, the implementation of the IIMS and a feasibility study are introduced in the following section 4.1, while its assessment is conducted in section 4.2).

\subsection{Feasibility study in a demonstration case}

After the domain of mechatronic PSS was analyzed, the implementation of the core concepts in the xPPU demonstration case (cf. section 2.2) was conducted. The IIMS was developed based on the ISO 10013-12 standard (ISO, 2001), which provides detailed guidelines for qualitative manual development and its maintenance. The developed IIMS is available as structured, hard copy manuals and forms containing 70 pages in total (for further details, cf. section 3.3). We expect a simplified integration into other management systems of organizations with the realization of such an IIMS. After performing a fictitious innovation implementation process, the observations were documented. In the following, insights are briefly outlined.

Innovation Implementation Context: Starting with the innovation implementation context, an organization chart was modeled. In mechatronic PSS, the reflection of mechanical, electrical, and software engineers is inevitable. Whether an innovation results in a small change (re-design) or a radical change (new development) is irrelevant, as cyclic changes are essential for the implementation of successful innovations for any PSS (Fricke et al., 2000; Koltun et al., 2018). Furthermore, we suggest to appoint an innovation implementation manager, who is aware of the guidelines for implementing innovations and controls their consideration. Finally, the innovation implementation context captures operations that are not part of the innovation implementation process itself, e.g. semi-annual review meetings or other socio-technical practices which make sure that the activities of the companies are constantly monitored, evaluated and possibly redirected. This can be done through technical support systems, external consulting or internal review meetings which take place when a certain level of insufficiency is expected. Innovation Implementation Process: Due to customer requests (requirements), the extension of the Pick and Place Unit has been identified by the PSS enterprise as the overarching innovation, i.e. mechanical, electrical, and software adaptations are required. The potential added value of this innovation is to increase productivity and quality. On the contrary, the risk of a non-optimal implementation can lead 
to a longer system downtime. In order to achieve this, an innovation implementation plan based on the ISO 9001 standard (ISO, 2015) has been developed. This plan initially provides a virtual verification on the basis of interdisciplinary modeling (cf. Kernschmidt and Vogel-Heuser, 2013). Operations, such as the development of a requirement model and a model library with mechatronic variants and versions, are therefore derived. Furthermore, a mapping matrix that can be used collaboratively by engineers has to be created. IT implementation options are expected from this matrix. These options are evaluated with regard to technical uncertainty of the innovation and the cost of a potential system breakdown; i.e. we therefore intend to run simulations. During settlement meetings between the engineering disciplines, a decision should be made regarding the implementation option. Knowledge deficits regarding the innovation within the organization are addressed. If knowledge deficits are found, further steps are discussed, e.g. recruiting of specialists or acquiring knowledge software products. These options are discussed in parallel, and approved by management. The remaining planning of the innovation implementation is done subsequently. Documentation for quality assurance control is produced thereafter in order to ensure the quality of the implementation.

Key Performance Indicators: KPIs are defined and their handling in borderline cases is specified in order to approve fulfillment of the innovation implementation requirements. This allows the organization to preserve information in real time, and save historic values with the frequency that the organization determines to be useful.

Innovation Implementation Management System: Once the processes are defined, the IIMS of the organization is developed, detailing how to effectively perform each of the defined activities by means of different procedures. The IIMS is structured as defined in subsection 3.3 and contains 70 pages. This takes the previously introduced fictitious innovation implementation process into account.

\subsection{Assessment, discussion of the results and improvements}

In the following, we approve the conceptual approach in relation to the identified challenges in section 2 . Thereby, the necessity to integrate technical and socio-technical aspects has been derived in order to support effective innovation implementation processes during the entire life-cycle of mechatronic PSS. The conceptual approach is therefore presented in section 3 . The core element of the presented approach is the IIMS. The generic framework is able to consider different innovation contexts and therewith relevant implementation KPIs. In this paper, we confirm the feasibility in a representative demonstration case for mechatronic PSS (cf. section 4.1). The IIMS has therefore been developed as hard copy manual instruction that follows the guideline of an international standard.

During a workshop of four scientific experts from different disciplines, i.e. industrial engineering, organization studies, and management sciences, we assessed the approach and the respective comprehensibility, applicability, and transferability of the demonstration case. Although we are aware that this workshop cannot provide fully valid statements, this exploratory approach pointed to these key observations: (a) The IIMS can serve as a basis for organizations, e.g. collaborative engineers, to foster both technical innovations and effective collaboration in organizations. (b) However, we foresee that improvements must be made for acceptance and applicability of the IIMS itself when transferring the approach to industrial applications. While the integrated concepts allow transferability and customized specifications, the development of the IIMS must be revised and supported. At the current IIMS stage, we expect a low level of industrial acceptance due to the high development effort of the IIMS. As a consequence, future research of the authors will focus on industrial assessment by implementing the concepts with other technical systems, i.e. a software-based management system. We expect a digital industrial management system or even the automated generation of IIMS. During the assessment in collaboration with industrial partners, the usability of the developed concepts and the IIMS can be adapted accordingly. Another further step is to also include external stakeholders, e.g. users or customers in the approach. They are important sources for innovations and organizations need to learn how to make use of their knowledge and ideas. Adding external stakeholders to the IIMS can support organizations in integrating them into the innovation implementation process.

\section{CONCLUSION AND OUTLOOK}

To keep up with global market dynamics, mechatronic PSS require innovations. However, frequent ineffective implementation of innovations caused organizations to fail to achieve the potential benefit of 
innovations. While the reasons for this are manifold, this paper points out the insufficient integration of technical and organizational aspects during the development of mechatronic PSS.

Innovation implementation processes are non-deterministic, which implies that there is not only the one approach but also many others. With the aim of supporting companies in the mechatronic PSS domain during the modelling of innovation processes, the approach in this paper builds on the work from a collaborative research center of the authors. Various methods and models are integrated into an innovation implementation process and context model. These models allow the capture of technical challenges, such as variant \& version, compatibility and inconsistency management. However, interdependence between the components implies further dependencies among the stakeholders, making the consideration of organizational and social aspects inevitable. The organizational environment, in which a specific technical system implementation takes place, can facilitate or hinder the innovation implementation process depending on the extent to which the specific formal rules and informal practices are considered. Therefore, it is important to reflect on organizational characteristics to facilitate effective innovation implementation.

In order to apply this approach, an Innovation Implementation Management System (IIMS) has been developed. The IIMS describes a management system that aims to effectively manage innovation implementation within an organization. By assessing the IIMS in a demonstration case in a workshop of domain experts, this paper comprises both technical and social characteristics in the context of mechatronic PSS. In summary, the presented approach can support an effective innovation implementation process, while the IIMS allows practitioners individual alignments in the future. However, before a transfer to industrial practice, our future research will be focused on (1) the consideration of external PSS stakeholders and, therewith, repetitive adaption to the concept. (2) We aim at investigating the acceptance and usability of the developed IIMS within industrial environments.

\section{REFERENCES}

Adolfsson, E. T., Smide, B., Gregeby, E., Fernström, L. and Wikblad, K. (2004), “Implementing empowerment group education in diabetes", Patient Education and Counseling, Vol. 53 No. 3, pp. 319-324. https://doi.org/10.1016/j.pec.2003.07.009

Aiman-Smith, L. and Green, S. G. (2002), "Implementing new manufacturing technology: The related effects of technology characteristics and user learning activities”, Academy of Management Journal, Vol. 45 No. 2, pp 421-430. https://doi.org/10.5465/3069356

Amaya, A. A., Liao, Y.-K. and Chang, S. (2018), "The effects of innovation implementation and speed to market on the relationship between team sense-making, trust, and npd success", International Journal of Innovation Management, p. 1950029. https://doi.org/10.1142/S1363919619500294

Aurich, J. C., Fuchs, C. and Wagenknecht, C. (2006), "Life cycle oriented design of technical product-service systems”, Journal of Cleaner Production, Vol. 14 No. 17, pp. 1480-1494. https://doi.org/10.1016/j.jclepro.2006.01.019

Avgerou, C. (2001), "The significance of context in information systems and organizational change", Information systems journal, Vol. 11 No. 1, pp. 43-63. https://doi.org/10.1046/j.1365-2575.2001.00095.x

Browning, T. R. (2001), "Applying the design structure matrix to system decomposition and integration problems: a review and new directions”, IEEE Transactions on Engineering management, Vol. 48 No. 3, pp. 292-306. https://doi.org/10.1109/17.946528

CEN 2013. "Innovation management - part 1: Innovation management system", Standard CEN/TS 165555-1:2013, European Committee for Standardization. https://standards.cen.eu/

Dong, L., Neufeld, D. J. and Higgins, C. (2008), "Testing klein and sorra's innovation implementation model: an empirical examination", Journal of Engineering and Technology Management, Vol. 25 No. 4, pp. $237-255$. https://doi.org/10.1016/j.jengtecman.2008.10.006

Eckerson, W. W. (2006), “Creating effective kpis”, Information Management, Vol. 16 No. 6 p. 15.

Edmondson, A. C., Bohmer, R. M. and Pisano, G. P. (2001), "Disrupted routines: Team learning and new technology implementation in hospitals”, Administrative Science Quarterly, Vol. 46 No. 4, pp. 685-716. https://doi.org/10.2307/3094828

Feldmann, S., Kernschmidt, K. and Vogel-Heuser, B. (2014), "Combining a sysml-based modeling approach and semantic technologies for analyzing change influences in manufacturing plant models", Procedia CIRP, Vol. 17, pp. 451-456. https://doi.org/10.1016/j.procir.2014.01.140

Fricke, E., Gebhard, B., Negele, H. and Igenbergs, E. (2000), “Coping with changes: causes, findings, and strategies", Systems Engineering, pp. 169-179.

Friedberg, E. (1997), “Local orders: dynamics of organized action”, Jai Press. 
Gunasekaran, A., Marri, H. B., McGaughey, R. and Grieve, R. (2001), "Implications of organization and human behaviour on the implementation of cim in smes: an empirical analysis", International Journal of Computer Integrated Manufacturing, Vol. 14 No. 2, pp. 175-185. https://doi.org/10.1080/09511920150216297

ISO (2001), "Guidelines for quality management system documentation”, Standard ISO/TR 10013:2001, International Organization for Standardization. https:/www.iso.org/standard/26978.html/

ISO (2015), “Quality management systems - requirements”, Standard ISO 9001:2015, International Organization for Standardization. https://www.iso.org/standard/46486.html

Kernschmidt, K. and Vogel-Heuser, B. (2013), “An interdisciplinary SysML based modeling approach for analyzing change influences in production plants to support the engineering”, IEEE CASE, Madison, US-WI. https://doi.org/10.1109/CoASE.2013.6654030

Klein, K. J., Conn, A. B. and Sorra, J. S. (2001), "Implementing computerized technology: An organizational analysis", Journal of Applied Psychology, Vol. 86 No. 5, pp. 811. https://doi.org/10.1037/0021-9010.86.5.811

Klein, K. J. and Knight, A. P. (2005), "Innovation implementation: Overcoming the challenge”, Current directions in psychological science, Vol. 14 No. 5, pp. 243-246. https://doi.org/10.1111/j.0963-7214.2005.00373.x

Klein, K. J. and Sorra, J. S. (1996), “The challenge of innovation implementation”, Academy of management review, Vol. 21 No. 4, pp. 1055-1080. https://doi.org/10.5465/amr.1996.9704071863

Koltun, G., Neumann, E.-M., Kattner, N., Bauer, H., Lindemann, U., Reinhart, G. and Vogel-Heuser, B. (2018), "Cyclic Management of Innovative PSS Changes: An Integrated and Interdisciplinary Engineering View", 2018 IEEE International Systems Engineering Symposium (ISSE), IEEE. https://doi.org/10.1109/SysEng.2018.8544384

Langer, S. F. and Lindemann, U. (2009), "Managing cycles in development processes-analysis and classification of external context factors", DS 58-1: Proceedings of ICED 09, the 17th International Conference on Engineering Design, Vol. 1, Design Processes, Palo Alto, CA, USA, 24.-27.08. 2009, pp. 539-550.

McGrath, R. G., Tsai, M.-H., Venkataraman, S. and MacMillan, I. C. (1996), "Innovation, competitive advantage and rent: a model and test”, Management Science, Vol. 42 No. 3, pp. 389-403. https://doi.org/10.1287/mnsc.42.3.389

Moldaschl Manfred, (2007), "Institutional Reflexivity - An institutional approach to measure innovativeness of firms", Papers and Preprints of the Department of Innovation Research and Sustainable Resource Management 2/2007. http://archiv.tu-chemnitz.de/pub/2007/0180

Moore, J. E., Mascarenhas, A., Bain, J. and Straus, S. E. (2017), "Developing a comprehensive definition of sustainability", Implementation Science, Vol. 12 No. 1, p. 110. https://doi.org/10.1186/s13012-017-0637-1

Neely, A. (2007), "The servitization of manufacturing: an analysis of global trends", 14th European Operations Management Association Conference, Turkey Ankara, pp. 1-10. https://doi.org/10.1.1.505.2210

OECD, E. (2005), Oslo manual, Guidelines for Collecting and Interpreting Innovation Data. https://doi.org/10.1787/9789264013100-en

Reif, J., Koltun, G., Drewlani, T., Zaggl, M., Kattner, N., Dengler, C., Basirati, M., Bauer, H., Krcmar, H., Kugler, K., Brodbeck, F., Lindemann, U., Lohmann, B., Meyer, U., Reinhart, G. and Vogel-Heuser, B. (2017), Modeling as the basis for innovation cycle management of PSS: Making use of interdisciplinary models, 2017 IEEE International Systems Engineering Symposium (ISSE), IEEE, pp. 371-376. https://doi.org/10.1109/SysEng.2017.8088310

Repenning, N. P. (2002), "A simulation-based approach to understanding the dynamics of innovation implementation”, Organization Science, Vol. 13 No. 2, pp. 109-127. https://doi.org/10.1287/orsc.13.2.109.535

Teece, D. J. (1986), "Profiting from technological innovation: Implications for integration, collaboration, licensing and public policy", Research policy, Vol. 15 No. 6, pp. 285-305. https://doi.org/10.1016/0048-7333(86)90027-2

Vogel-Heuser, B., Legat, C., Folmer, J. and Feldmann, S. (2014), "Researching Evolution in Industrial Plant Automation: Scenarios and Documentation of the Pick and Place Unit", Technical Report TUM-AIS-TR-01-14-02, Technische Universität München. https://mediatum.ub.tum.de/node?id=1208973

Zaggl, M., Schweisfurth, T. and Herstatt, C. (2019), "The dynamics of openness and the role of user communities: A case study in the ecosystem of open source gaming handhelds", IEEE Transactions on Engineering Management.

\section{ACKNOWLEDGMENTS}

This work was supported by the German Research Foundation (Deutsche Forschungsgemeinschaft, DFG) collaborative research center Sonderforschungsbereich SFB 768 "Managing cycles in innovation processes - Integrated development of product-service-systems based on technical products". 